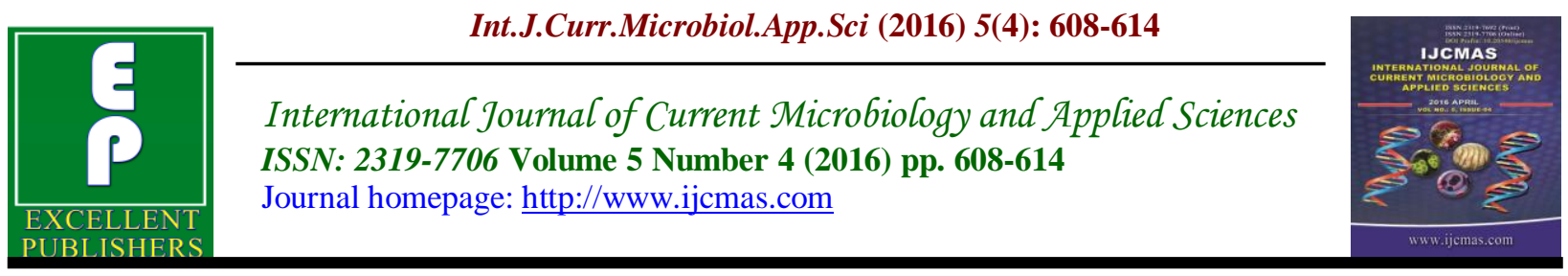

Original Research Article

http://dx.doi.org/10.20546/ijcmas.2016.504.069

\title{
Studies on Microbial Diversity of a Soda Lake in India by Winogradsky Column Technique
}

\author{
Harshil H. Bhatt ${ }^{1}$, Bhimaraj M. Sharma ${ }^{2}$ and Vivek N. Upasani ${ }^{3 *}$ \\ ${ }^{1}$ Department of Biotechnology, Kadi SarvaVishwavidyalaya, Gandhinagar 382015, India \\ ${ }^{2}$ Fisheries Officer, Commissioner of Fisheries, Bharuch, India. \\ ${ }^{3}$ Department of Microbiology, M. G. Science Institute, Navrangpura, Ahmedabad 380009, India \\ *Corresponding author
}

\begin{abstract}
A B S T R A C T
Keywords

Microbial diversity, soda lake, Sambhar Salt Lake (SSL), Winogradsky Column, t-RFLP.

\section{Article Info}

Accepted:

19 March 2016 Available Online:

10 April 2016

Halophilic organisms are found in habitats with a high concentration of salt (mainly $\mathrm{NaCl}$ ) such as the Great Salt Lake, Utah; Owens Lake, California; the Dead Sea, soda lakes such as Lake Magadii, Kenya and Sambhar Salt Lake, India; marine salterns across the globe, etc. Organisms living in such habitat require high salt concentration $(5-25 \% \mathrm{NaCl})$ and/or alkaline $\mathrm{pH}$ for growth. Algae, archaea, purple and green sulfur bacteria are the dominant microflora of these extreme habitat. Samples were collected from Sambhar Lake and microbial diversity was examined by cultivating halophilic organisms in Winogradsky Column. Successive changes in the column lead to changes in diversity also. Here we report on microbial diversity based on photomicrography and t-RFLP method. This is the first report on the use of Winogradsky column technique for enrichment and study the microbial diversity of Sambhar Salt Lake.
\end{abstract}

\section{Introduction}

Sergei Winogradsky, a Russian microbiologist developed "Winogradsky Column" technique a simple way to grow and study the complex microbial interactions in natural samples. Each organism is dependent on the other under given conditions for growth; inorganic salts, organic matter, and light are the energy sources. This technique is a classical way of showing the diversity of microbes based on their metabolic and physiological requirements. It remains an important display of photoautotrophy, chemoautotrophy and chemoorganotrophy in aquatic ecosystem.

The soda lakes are wide spread in the arid and desert regions around the world. The African Rift valley lakes, Transbaikal lakes (Russia), Kulunda steppe soda lakes (Russia), Great Salt Lake (USA), Sambhar Salt Lake (India), etc. are some of the famous lakes that have been studied for their microbial diversity (Grant and Tindall, 
1986; Grant et al., 1998; Gorlenko et al., 2010; Samylina et al., 2014). The adaptation of haloalkaliphilic bacteria to the environmental pressures such as high $\mathrm{pH}$, salt concentration, temperature, etc., in soda lakes, and their role in biogeochemical cycle has been described by Sorokin et al. 2014 (Sorokin et al., 2014). Study on the diversity of Purple sulfur bacteria (mainly genus Ectothiorhodhospira) has been reported from Transbaikal lakes.

We have developed several Winogradsky columns to enrich and study the diversity of extremely halophilic bacteria and algae present in the Sambhar Salt Lake brines and soil. The change in color of the column, and morphological forms due to the effect of temperature, salt concentration, $\mathrm{pH}$ and light intensity over a period of time was monitored. Several strains of haloalkaliphilic archaea, anoxygenic purple sulfur bacteria, green sulfur bacteria and cyanobacteria were observed and few were characterized.

This study, will be useful for others to understand the exploration of the rich microbial diversity found in this unique extreme environment,

\section{Materials and Methods}

\section{Sample Collection}

Soil and brine samples (various densities/salt concentrations) were collected from Devyani Kyars (pans), Sambhar Lake, Rajasthan during May and November months. Samples were stored at $4{ }^{\circ} \mathrm{C}$.

\section{Enrichment by Winogradsky Column Technique}

A few cylinders were prepared using Trüper and Imhoff medium (1978) containing 16.0
$(\% \mathrm{w} / \mathrm{v}) \mathrm{NaCl}$ and inoculated with the pink to red coloured brine of high density for enrichment of photosynthetic bacteria. The medium composition $(\mathrm{g} / \mathrm{L})$ is as follows: calcium chloride, 0.05;magnesium chloride, 0.10 ; potassium dihydrogen orthophosphate, 0.50; ammonium chloride, 0.80; sodium sulfate, 20.00; sodium carbonate, 20.00; sodium chloride, 160.00; yeast extract, 0.50; sodium succinate, 2.00; vitamin solution, $1.00 \mathrm{ml}$; SLA solution, $1.00 \mathrm{ml}$. Final $\mathrm{pH}$ was adjusted to 8.5 with $\mathrm{NaHCO}_{3}$. Organic and inorganic media were autoclaved separately.

Composition of SLA solution ( $\mathrm{g} / \mathrm{L})$ : sodium ethylene diamine tetra acetic acid, 3.00; iron sulfate, 1.10 ; cobalt chloride, 0.19; manganese chloride, 0.10 ; zinc chloride, 0.07; sodium molybdate dihydrate, 0.018 ; nickel chloride, 0.02; boric acid, 0.30; copper chloride, 0.002.The same medium with $5 \%(\mathrm{w} / \mathrm{v}) \mathrm{NaCl}$ concentration resulted in the enrichment of haloalkaliphilic microalgae. Other columns were inoculated with low density brine (green coloured) for microalgal cultivation.

The soil, brine sample (s) $200 \mathrm{ml}$, chalk, and Whatman no. 1 paper strips were added to a $2 \mathrm{~L}$ glass measuring cylinder and the final volume was made to $2 \mathrm{~L}$ with the above mentioned medium. It was then incubated in sunlight for 3-4 months and growth was observed periodically.

\section{Morphological Studies}

The samples collected from the site and enriched in column were centrifuged; wet mount were observed microscopically and photomicrographs were taken using 10X, 45X and 100X objectives with a Lawrence and Mayo binocular microscope attached with a Nikon 6000P camera. 


\section{t-RFLP for Algal Diversity}

Terminal Restriction Fragment Length Polymorphism (t-RFLP) is a molecular biology technique used to study microbial diversity using automated DNA analyser. Genomic DNA was isolated from the biomass collected from green brine samples as well as enriched microalgal culture obtained by inoculating the same sample into Algae Culture Broth (ACB) medium(Hi-media). The ITS fragment ( 800 bp) was amplified using high-fidelity PCR polymerase with 6-carboxy fluorescein (FAM)-labelled primers. The PCR product was subjected to restriction digestion. The fluorescently labelled $t-R F s$ were size separated on an automated sequencer using an internal size standard. The t-RFLP electropherograms were analyzed with GeneScan 3.7 software (Applied Biosystems). This analysis was carried out at Chromous Biotech Pvt. Ltd, Bangalore.

\section{Results and Discussion}

\section{Sampling and Microscopic Observations}

The Sambhar Lake is an intermittent salt lake, with varying physicochemical properties depending upon the season and site. Sambhar Lake has shallow solar pans and salinity of the pans ranges from 5.0 to $30 \%$ depending on the salt production stage, Samples were collected from Devyani Kyars with salinity ranging from was 10-25.0 (\% w/v NaCl), so that both algae and bacterial could be enriched from the samples. The microbial diversity changes with season as reported in these tropical desert lakes (Jakher et al., 1990; Kumar, 2008; Upasani and Desai, 1990; Upasani, 2008) hence we have collected samples during two different seasons (summer and early winter). The colour of the brine indicated that during summer season, bacterial diversity was dominant (pink brine), and during winter season, algal diversity was dominant (green brine). The brine samples collected were green, orange to red, or purple pink depending on the salt concentration and $\mathrm{pH}$. The various forms (oval, rod-shaped, spiral and filamentous) of algae were observed in the green coloured brine samples as shown in Fig. 1. The filamentous and spiral forms were less in number as compared to the other forms. The size of filamentous spiral forms was as long as $40-50 \mu \mathrm{m}$, unusual forms of square shaped cells in chain were also observed. The microbial cell density as well as diversity was astonishingly high in the natural samples. Most of the algae were prokaryotic, however eukaryotic algae belonging to the genus Arthrospira (typical spiral morphology with terminal ovalshaped akinete), and Dunaliella (Fig. 1D) were also observed.

\section{Enrichment by Winogradsky Column Technique}

We opted for Winogradsky column technique which supports growth of both bacteria and algae. Use of brines of different densities (salt concentration) allowed the development of cyanobacteria/algal flora and phototrophic purple sulfur bacteria as described by several researchers. The columns were set-up in May and inoculated with pink/red brine and soil samples. After about a month, purple-pink colour growth was initially observed at the bottom. Further, incubation lead to dense growth in the column (bloom) giving it a dark purple-pink colour (Fig. 2A). Microscopic observation revealed the presence of sheathed bacteria, and the curved or slightly spiral anoxygenic purple sulfur bacteria.

We observed the presence of the anoxygenic purple sulfur bacteria in the natural as well as the enriched samples, which belong to the genus Ectothiorhodhospira, reported by 
Imhoff and Trüper (1977) from Lake Magadii, Kenya. One species was identified as E. halophila (Imhoff et al., 1978). Extremophilic anoxygenic phototrophic bacterial diversity from soda lakes was reviewed by Madigen (Madigen, 2003).

During the first few months (November to January) there was not much change in the column that was inoculated with the algal sample, probably due to the low temperatures $\left(10-20{ }^{\circ} \mathrm{C}\right)$. However, after February as the temperature gradually increased (max. $25-30{ }^{\circ} \mathrm{C}$ ) and there was a sudden remarkable change with the development of light green colour in the column (Fig. 2B). Upon incubation of more than 3-4 months, the column turned into dark green colour, and the rod-shaped cyanobacteria became dominant form in the column (Fig. 3).

Fig.1 Photomicrographs of Microalgae from the Natural Samples

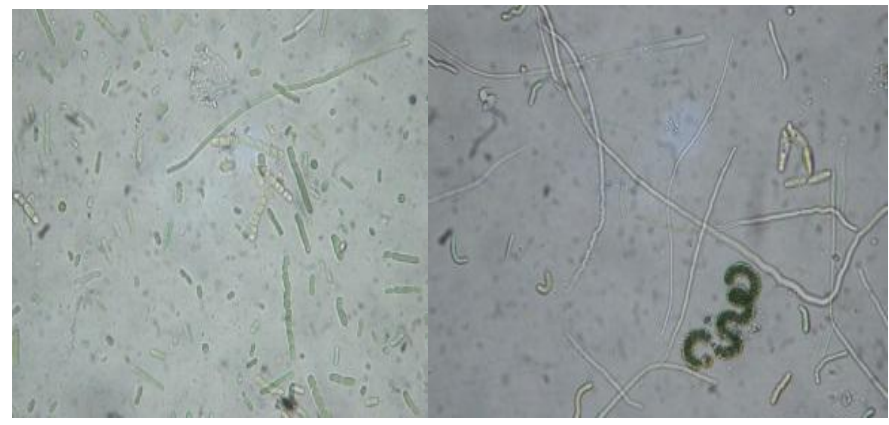

(A)

(C)

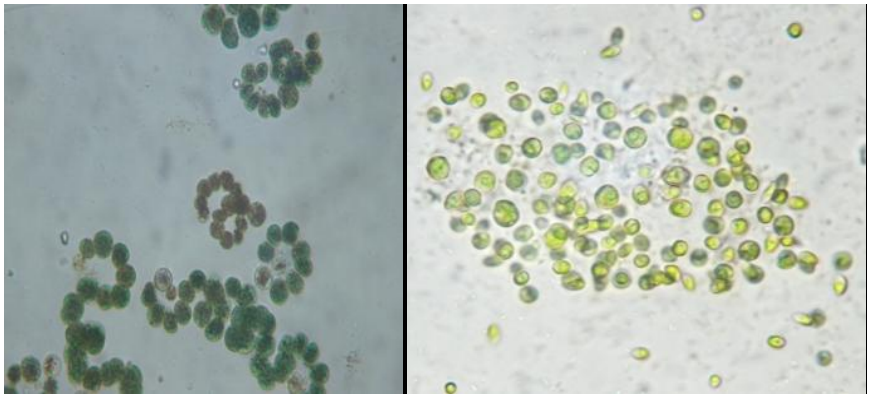

(B)

(D)

Fig.2 A) Enrichment of Anoxygenic Phototrophic (Purple Sulfur Bacteria), B) Enrichment of Microalgae by Winogradsky Column Technique
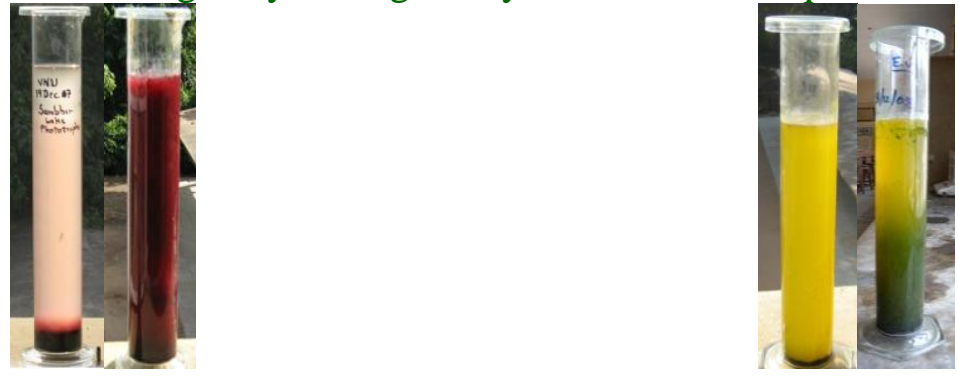

(A)

(B) 
Fig.3 Photomicrographs of Cyanobacteria from Winogradsky Column

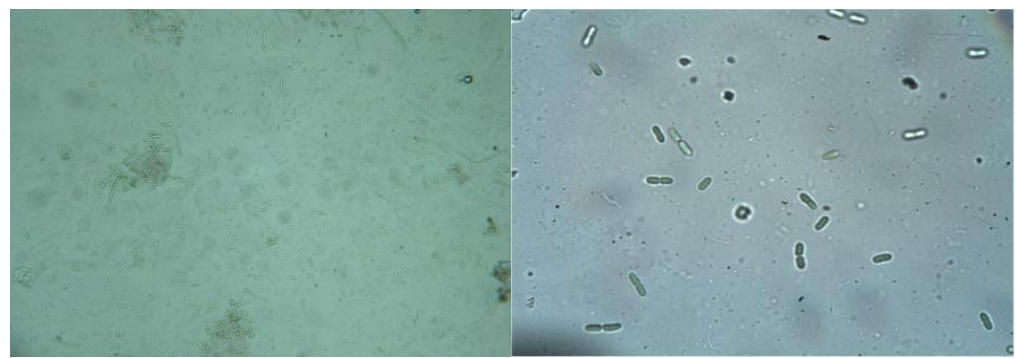

Fig.4A t-RFLP from Algal Sample

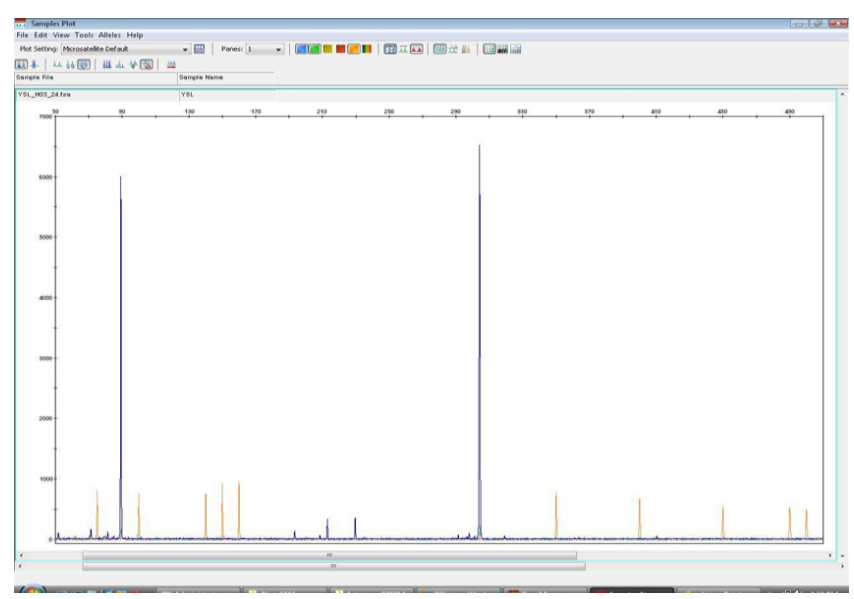

Fig.4B t-RFLP from Enriched Sample

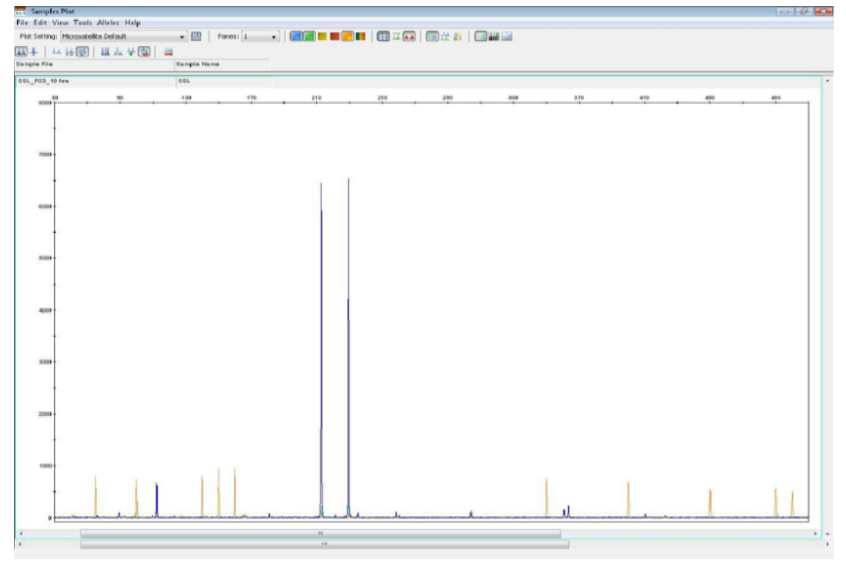

There were successful in the isolation and characterization of Euhalothece sp. from the enriched green cultures from Winogradsky column (Bhatt et al., 2016). The isolation of Dunaliella sp., an eukaryotic alga commonly found in hypersaline lakes has been reported from Sambhar lake by Sharma et al., 2012. The presence of Akinete (thick walled, resting cells) in Spirulina $s p$. (Arthrospira sp.) is the distinctive 
morphological feature, and its presence has been described in Arthrospira maxima. Cyanobacterial biodiversity in India has been reviewed by Thajuddin and Subramanian (2005); however specific information on these organisms from Sambhar Lake is not included.

\section{t-RFLP for Algal Study}

The use of algal specific primers ensured amplification of algal $18 \mathrm{~S}$ rDNA, which was size separated. The use of 6-carboxy fluorescein (FAM)-labelled primers gave blue colour in Genescan analysis; hence the number of blue peaks in t-RFLP's was equivalent to the number of algal species present. Orange peaks are internal size standards. The results revealed the presence of six (6) and three (3) algal species in the brine sample and enriched samples, respectively (Fig.4a and 4b).

We have used t-RFLP technique to know the cultivable and non-cultivable species from the sample. From the t-RFLP data, species count was calculated as six (6) in the sample collected analysis, which showed the presence of three (3) algal species in the enriched sample. This sample was inoculated in specific algal growth media and incubated for 3 weeks then enriched samplewas used for t-RFLP, it shows that three algal species were unable to grow under the growth conditions used in our laboratory. Among the three algal species that could be cultivated using this technique one was identified as Euhalothece sp., and two belonged to the genera Spirulina and Dunaliella, respectively. Research work on the isolation and identification of these microorganisms for biotechnological applications is being undertaken by our laboratory.
The present study clearly shows that the Winogradsky Column technique can be very useful for the enrichment of both microalgae and bacteria to explore their diversity from hypersaline soda lakes. The microbial succession was similar to that described for other aquatic environments. The use of different samples, media and cultural conditions allows the enrichment of specific group of microbes (microalgae and phototrophic purple sulfur bacteria as observed in our studies). This is the first report on the use of this well-known technique for microbiological studies from a soda lake in India.

\section{Acknowledgement}

The authors thank the authorities at M. G. Science Institute and Ahmedabad Education Society (AES) for proving the laboratory facilities. The grants from UGC (Minor research project no. F. No. 47-590/13, WRO to VN Upasani), and DBT (New Delhi) under the "Star College Scheme" is duly acknowledged.

\section{References}

1. Adams, D.G., Duggan, P.S. 1999. Heterocyst and akinete differentiation in cyanobacteria. New phytol., 144: 3-33.

2. Bhatt, H.H., Renu, P., Upasani, V.N. 2016. Isolation and Characterization of a Halophilic Cyanobacterium Euhalothece SLVH01 from Sambhar Salt Lake, India. Int. J. Curr. Microbiol. App. Sci., 5(2): 215-224.

3. Grant, W.D., Tindall, B.J. 1986. The Alkaline saline environments. In: Herbert RA, Codd GA, editors. Microbes in extreme environments. London: Academic Press, p. 25-54.

4. Grant, W.D., Jones, B., Duckworth, A., Owenson, G. 1998. Microbial diversity 
of soda lakes. Extremophile, 2: 191200.

5. Gorlenko, M.V., Buryukhaev, S.P., Matyugina, E.B., Borzenko, S.V., Namsaraev, Z.B., Bryantseva, I.A., Boldareva, E.N., Sorokin, D.Y., Namsaraev, B.B. 2010. Microbial Communities of the Stratified Soda Lake Doroninskoe (Transbaikal Region). Microbiol., 79: 410-421.

6. Imhoff, J.F., Trüper, H.G. 1977. Ectothiorhodospira halochloris sp. nov., a new extremely halophilic phototrophic bacterium containing bacteriochlorophyll b. Arch. Microbiol., 130: 238-242.

7. Imhoff, J.F., Hashwa, F., Trüper, H.G. 1978. Isolation of extremely halophilic phototrophic bacteria from the alkaline Wadi Natrun, Egypt. Arch. Hydrobiol., 84: 381-388.

8. Jakher, G., Bhargava, S., Sinha, R. 1990. Comparative limnology of Sambhar and Didwana lakes (Rajasthan, NW India) Hydrobiologia, 197: 245256.

9. Kompantseva, E.I., Bryantseva, I.A., Komova, A.V., Namsaraev, B.B. 2007. The Structure of Phototrophic Communities of Soda Lakes of the Southeastern Transbaikal Region. Microbiol., 76: 211-219.

10. Kumar, S. 2008. Conservation of Sambhar Lake- An important waterfowl habitat and a Ramsar Site in India. Proceedings of TAAL2007-The 12th World Lake Conference, 1509-1517.
11. Madigen, T.M. 2003. Anoxygenic phototrophic bacteria from extreme environments. Photosynth. Res., 76: 157-171.

12. Samylina, O.S., Sapozhnikov, F.V., Gainanova, O.Y., Ryabova, A.V., Nikitin, M.A., Sorokin, D.Y. 2014. Algo-Bacterial communities of the Kulunda Steppe (Altai Region, Russia) Soda Lakes. Microbiol., 83: 849-860.

13. Sorokin, Y.D., Berben, T., Melton, E.D., Overmars, L., Vavourakis, C.D., Muyzer, G. 2014. Microbial diversity and biogeochemical cycling in soda Lakes. Extremophile, 18: 791-809.

14. Sharma, P., Agarwal, V., Mohan, M.K., Kachhwaha, S., Kothari, S.L. 2012. Isolation and Characterization of Dunaliella Species from Sambhar Lake (India) and its Phylogenetic Position in the Genus Dunaliella Using 18S rDNA, Natl. Acad. Sci. Lett., 35: 207-213.

15. Thajuddin, N., Subramanian, G. 2005. Cyanobacterial biodiversity and potential applications in biotechnology. Curr. Sci. Sp. Ed., 89.

16. Upasani, V.N., Desai, S.G. 1990. Sambhar Salt Lake: chemical composition of brines and studies on haloalkaliphilic archeobacteria. Arch. Microbiol., 154: 589-593.

17. Upasani, V.N. 2008. Microbiological studies on Sambhar Lake (Salt of Earth) Rajasthan, India. In Proceedings of TAAL2007-The 12th World Lake Conference, $448-450$.

\section{How to cite this article:}

Harshil H. Bhatt, Bhimaraj M. Sharma and Vivek N. Upasani. 2016. Studies on Microbial Diversity of a Soda Lake in India by Winogradsky Column Technique. Int.J.Curr.Microbiol.App.Sci.5(4): 608-614. doi: http://dx.doi.org/10.20546/ijcmas.2016.504.069 